\title{
EVALUATING THE ANTI-STRESS POTENTIAL OF PROPOFOL IN ROAD TRANSPORTATION WELFARE USING BIO-MARKERS IN WEST AFRICAN DWARF GOATS
}

\author{
K. T. Biobaku ${ }^{1}$, B. S. Okediran ${ }^{2 *}$, A. T. Adebiyi ${ }^{3}$, A. Aremu ${ }^{4}$ and A. J. Atata ${ }^{4}$ \\ ${ }^{1}$ Department of Veterinary Pharmacology and Toxicology, University of Ilorin, Ilorin; ${ }^{2}$ Department of Veterinary \\ Physiology and Biochemistry; ${ }^{3}$ Department of Veterinary Physiology and Pharmacology, Federal University of \\ Agriculture, Abeokuta; ${ }^{4}$ Department of Veterinary Pathology, University of Ilorin, Ilorin
}

\begin{abstract}
Sixteen apparently healthy West African dwarf bucks were used in the study. They were randomly grouped into four with four animals each. Group one untreated non transported (non stressed control) control, group two was administered with propofol at $5 \mathrm{mg} / \mathrm{Kg}$ intramuscularly, group three was administered with ascorbic acid $500 \mathrm{mg} / \mathrm{kg}$ intramuscularly and group four non treated stressed control. Animals were carefully loaded in an open vehicle. The floor of the vehicle was cushioned to avoid the animals from sliding and injury. Then animals were subjected to a journey of 2hours at a speed of $40 \mathrm{~kg} / \mathrm{hr}$. Blood for haemotological analysis for full blood count was collected in bottles containing EDTA (ethylene diaminetetraacetic acid). While samples for assay of antioxidative enzymes were collected in bottles containing lithium heparin. The blood was also analysed superoxide dismutase (SOD), malonyldialdehyde (MDA), and glutathione -s- transferase (GST) respectively, using commercial Randox ${ }^{\circledR}$ kit. The packed cell volume $(\mathrm{PCV})$ showed significantly $(\mathrm{P}<0.05)$ higher $\mathrm{PCV}$ in the groups treated with propofol, ascorbic acid and none-stress control midway into the journey. The neutrophils -lymphocytes ratio (N: L) levels in was significantly higher at prior the journey. The levels of MDA were significantly $(\mathrm{P}<0.05)$ higher prior and at the end of the journey phases in the propofol treated group. The ascorbic acid group showed significantly $(\mathrm{P}<0.05)$ higher level of MDA at the mid phase of the journey. While the GST levels prior to journey were significantly $(\mathrm{P}<0.05)$ higher compare to the other phases in the propofol and ascorbic acid treated groups and none treated stressed control. In the SOD level was significantly $(\mathrm{P}<0.05)$ higher prior stage of the journey in the propofol treated group. this infer that propofol possess antistress effect and could be used to improve animal welfare at transportation. Conclusively, the propofol possess antistress effect that is similar in mechanism to ascorbic acid and could be used in amelioration of stress in short term stress in animals. It however advised that the withdrawal period of the drug is adhered to prevent residue of drug in the meat product.
\end{abstract}

Key words: Propofol, bio-marker, dwarf goat, welfare

\section{INTRODUCTION}

Transportation of animals is an inevitable practice of animal husbandry (Adenkola et al., 2009). Pre slaughter conditions of livestock causes complex psychological and physiological changes (Minka and Ayo, 2010).This might be as a result of acute alarm reaction caused by short term stress or general adaptative mechanism at long term stress. In Sub Saharan Africa transportation of animals is usually carried out either with lack of adherence to animal welfare laws or sometimes completely neglecting the laws (Ali et al., 2006).

A number of pharmacological agents were previously suggested by Ali and Qarawi (2002). While other authors suggested usage of ascorbic acid supplementation and other antioxidants Ayo et al., 2006; Adenkola et al., 2009; Minka and Ayo, 2010a ). Recently, Biobaku, (2015) observed and suggested the combination of xylazine and ascorbic acid could improve upon the welfare of bucks exposed to long term transportation stress and invariably quality of chevon.

In this study however propofol was experimented upon, an anesthetic agent which was found to have antioxidative property by improving the activity of antioxidative enzymes during stress condition Wen-fang et al. (2011). While Tomioka et al. (2011) found that propofol reduced both dilation and superoxide production in response to N-methyl-D- aspartate induced dilation. The objective of this study is to evaluate the possibility of usage of propofol as an antioxidative agent in short term road transportation stress of 2hours in West African Dwarf goats. The specific objective is to evaluate the stress ameliorative effect of protocol on some haematological and biochemical stress biomarkers of West African bucks exposed to short time stress.

\footnotetext{
*Corresponding e-mail address: okediranbabatunde@gmail.com
} 


\section{MATERIALS AND METHODS}

\section{Experimental Animal Welfare and Ethics}

Sixteen apparently healthy West African dwarf bucks were procured from Lafenwa livestock market, Abeokuta North local Government, Ogun State. The animals had the same body condition score of 3 and were in the age range of 1 to $1 \frac{1 / 2}{2}$ year respectively. The animals were housed using the semi-intensive method in which the animals. This was to ensure that stress is minimized. The animals were acclimatized for 2 weeks. The animals were fed on wheat bran, grass and clean drinking ad libitum .The animals were clinically examined and were prophylactically treated with penicillin and streptomycin each at $6 \mathrm{mg} / \mathrm{kg}$ and $10 \mathrm{mg} / \mathrm{kg}$. Anthelminthic drug albendazole was administered at $25 \mathrm{mg} / \mathrm{kg}$ orally. Ethical permission was sought from Faculty committee on research at the proposal presentation in Federal University of Agriculture, Abeokuta, Nigeria.

\section{Drug administration and experimental design}

The animals were randomly seperated into four groups with four animals each. Group one untreated non transported (non stressed control) control, group two was administered with propofol at $5 \mathrm{mg} / \mathrm{Kg}$ intramuscularly , group three was administered with ascorbic acid $500 \mathrm{mg} / \mathrm{kg}$ intramuscularly and group four non treated stressed control. The drug propofol (profol ${ }^{\circledR}$ ) was administered at $5 \mathrm{mg} / \mathrm{kg}$ using intramuscular route. The ascorbic acid (ascorbate ${ }^{\circledR}$ Agbara , Nigeria). The drug and supplement was administered prior to the journey.

\section{Loading of animals and transportation ethics}

The animals were carefully loaded in an open vehicle. The floor of the vehicle was cushioned to avoid the animals from sliding and injury. Also the floor lining is aimed at minimizing contact with urine and faeces. The animals were transported for 2 hours a speed of $40 \mathrm{~kg} / \mathrm{hr}$. This was in accordance to international laws and Animal Disease Act of 1988 in Nigeria. The animals were stocked at an area of $0.30 \mathrm{~m}^{2}$ per animal .This is also in conformity with the Animal Disease Act of 1988 of the Federal Republic of Nigeria.

\section{Blood Collection and Analysis}

A 21 guage syringe and needle was used to collect blood from the jugular after disinfection of the skin surface using methylated spirit. Four milliliters of blood was collected prior, mid and after the journey. The blood was collected in bottles containing lithium heparin. The blood was analysed for antioxidative enzymes (superoxide dismutase, malonyldialdehyde, and glutathione -s- transferase) using commercial Randox® kit made in England as previously adopted by Mohammed et al. (2007) respectively. Blood for haemotological analysis was collected in bottles containing EDTA (ethylene diaminetetraacetic acid). The blood sample were analysed for full blood using the method of Schalm and Jain (1986). While haemoglobin concentration was assessed using biochemical method using commercial Randox® test kit made in England.

\section{Statistical Analysis}

SPSS (Statistical Package Version 16) was used for the analysis and Analysis of Variance was the statistical tool used for the analysis. The level of significant $\mathrm{P}<(0.05)$ was considered significant

\section{RESULTS AND DISCUSSION}

The results of the study are as shown in figures $1-7$ below. The PCV showed significantly $(\mathrm{P}<0.05)$ higher $\mathrm{PCV}$ in the groups treated with propofol, ascorbic acid and non-stress control midway into the journey in figure 1. In figure 2 showed a similar trend of haemoglobin concentration as the PCV. In figure 3 which shows the WBC had significantly $(\mathrm{P}<0.05)$ higher at the end of the journey in the groups treated with propofol and ascorbic acid, while the stressed non treated control showed significantly $(\mathrm{P}>0.05)$ lower at the end of the journey. The $\mathrm{N}$ : L levels in figure 4 were significantly higher at prior to the journey. Figure 5 shows the levels of MDA were significantly $(\mathrm{P}<0.05)$ higher prior and at the end of the journey phases in the propofol treated group. The ascorbic acid group showed significantly $(\mathrm{P}<0.05)$ higher level of MDA at the mid phase of the journey. Figure 6 shows that the GST levels at the prior phase of the journey were significantly $(\mathrm{P}<0.05)$ higher when compare to the other phases in the propofol, ascorbic acid treated groups and none treated stressed control. In the figure 7 showed the SOD level was significantly $(\mathrm{P}<0.05)$ higher at prior stage of the journey in the propofol treated group.The none treated stressed control however although had significantly $(\mathrm{P}<0.05)$ levels prior to the journey the level is comparatively lower than other treatment groups in the study. 


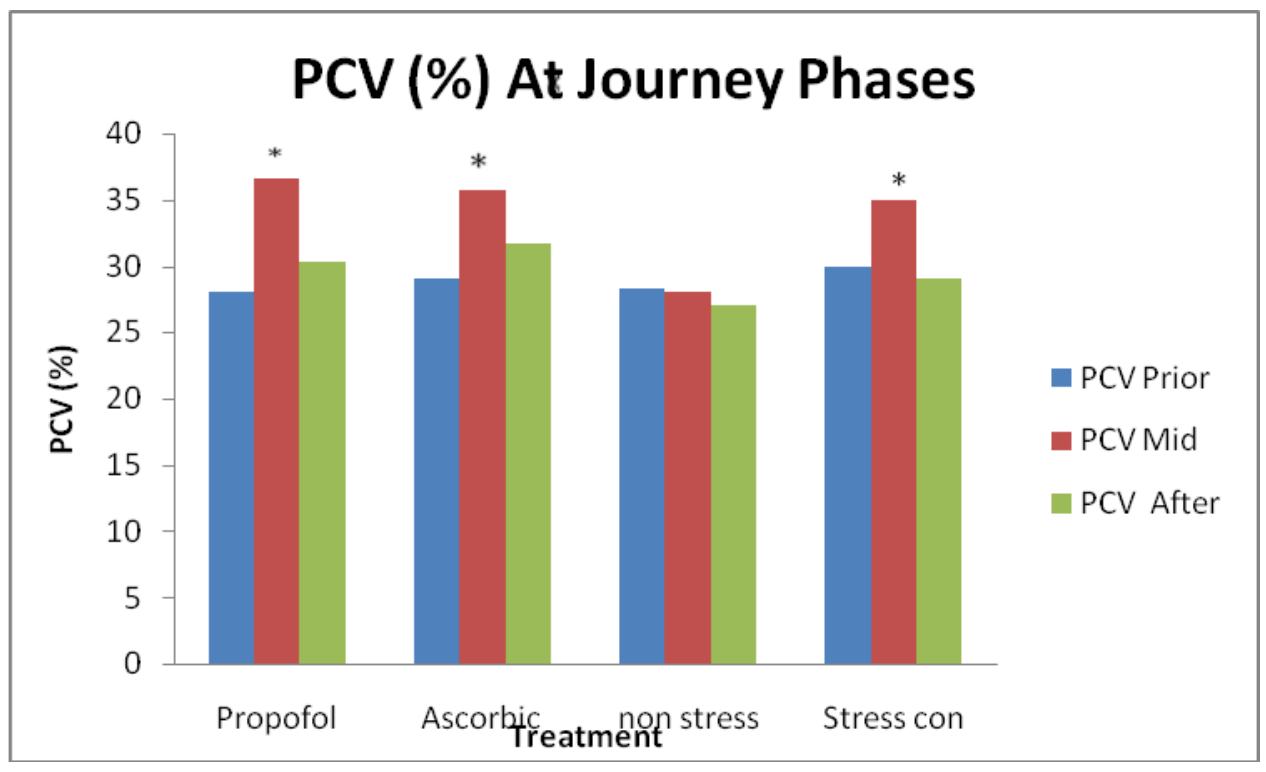

Figure 1. Shows the effect various treatment groups: Propofol $(5 \mathrm{mg} / \mathrm{kg})$ intramuscularly (IM), Ascorbic: ascorbic acid $(500 \mathrm{mg} / \mathrm{kg})(\mathrm{IM})$, non stress: non stress control, stress con: stressed control on means of PCV (\%) at phases of the experimental journey PCV Prior: PCV prior to the journey, PCV Mid: PCV midway into the journey and PCV After: $\mathrm{PCV}$ after the journey.

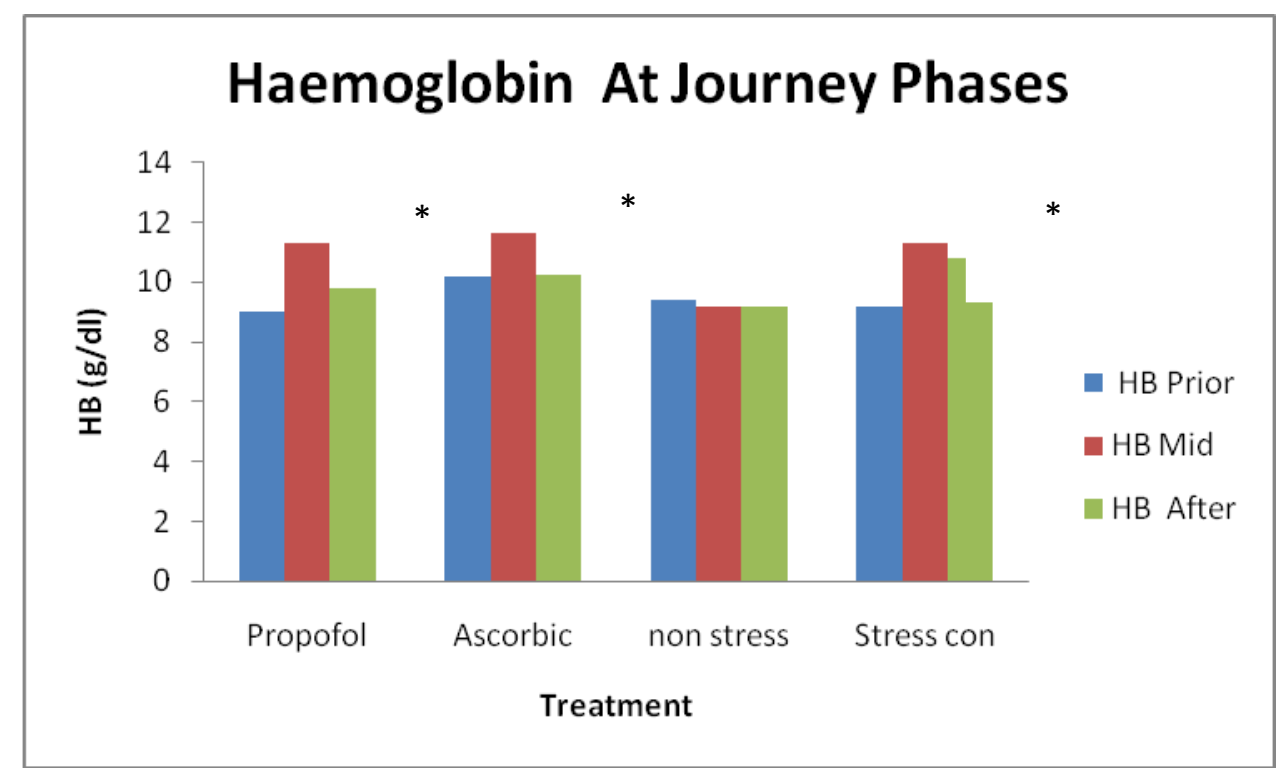

Figure 2. Shows the effect various treatment groups : Propofol $(5 \mathrm{mg} / \mathrm{kg})$ intramuscularly (IM),Ascorbic: ascorbic acid $(500 \mathrm{mg} / \mathrm{kg})(\mathrm{IM})$,non stress: non stress control, stress con: stressed control on means of $\mathrm{HB}$ (haemoglobin)(g/dl) at phases of the experimental journey HB Prior: HB prior to the journey HB Mid: HB midway into the journey and HB After: HB after the journey. 


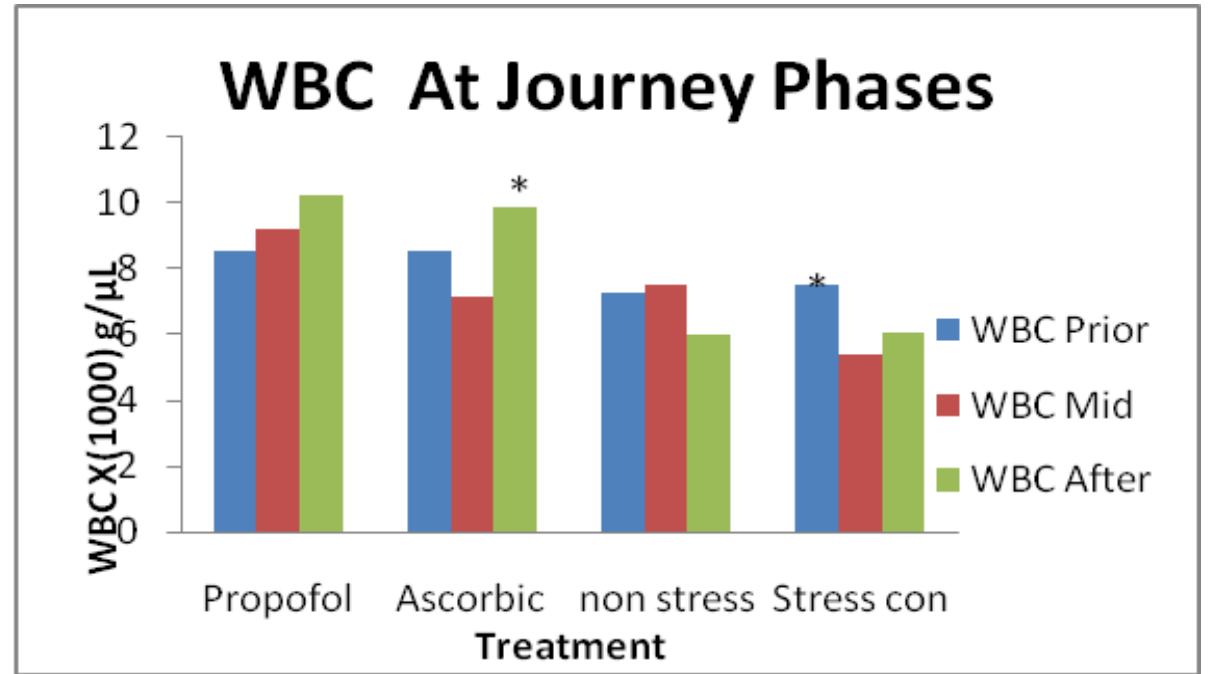

Figure 3. Shows the effect various treatment groups : Propofol $(5 \mathrm{mg} / \mathrm{kg})$ intramuscularly (IM),Ascorbic: ascorbic acid $(500 \mathrm{mg} / \mathrm{kg}$ ),non stress: non stress control, stress con: stressed control on means of WBC (white blood cells) $\mathrm{x}\left(10^{3}\right) \mathrm{g} / \mu \mathrm{l}$ at phases of the experimental journey WBC Prior: WBC prior to the journey WBC Mid: WBC midway into the journey and WBC After: WBC after the journey .

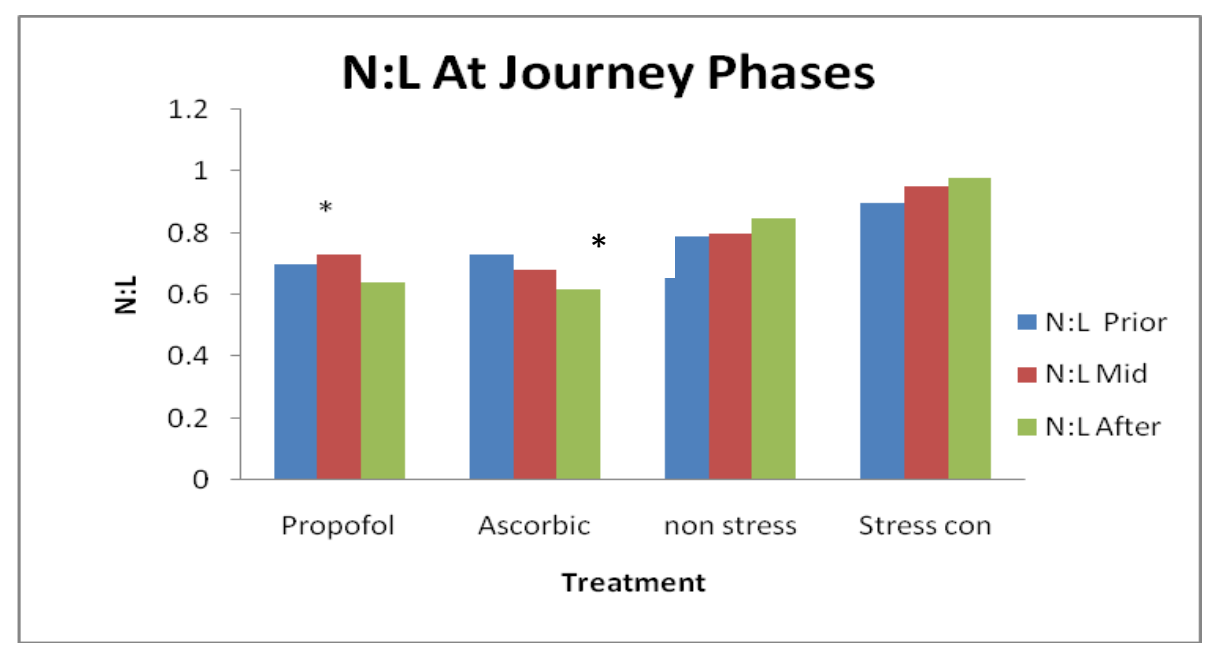

Figure 4. Shows the effect various treatment groups : Propofol $(5 \mathrm{mg} / \mathrm{kg})$ intramuscularly (IM), Ascorbic: ascorbic acid $(500 \mathrm{mg} / \mathrm{kg}$ ) (IM),non stress: non stress control, stress con: stressed control on means of N:L (neutrophilslymphocytes ratio) at phases of the experimental journey N:L Prior: N:L prior to the journey N:L Mid: N:L midway into the journey and N:L After: N:L after the journey . 


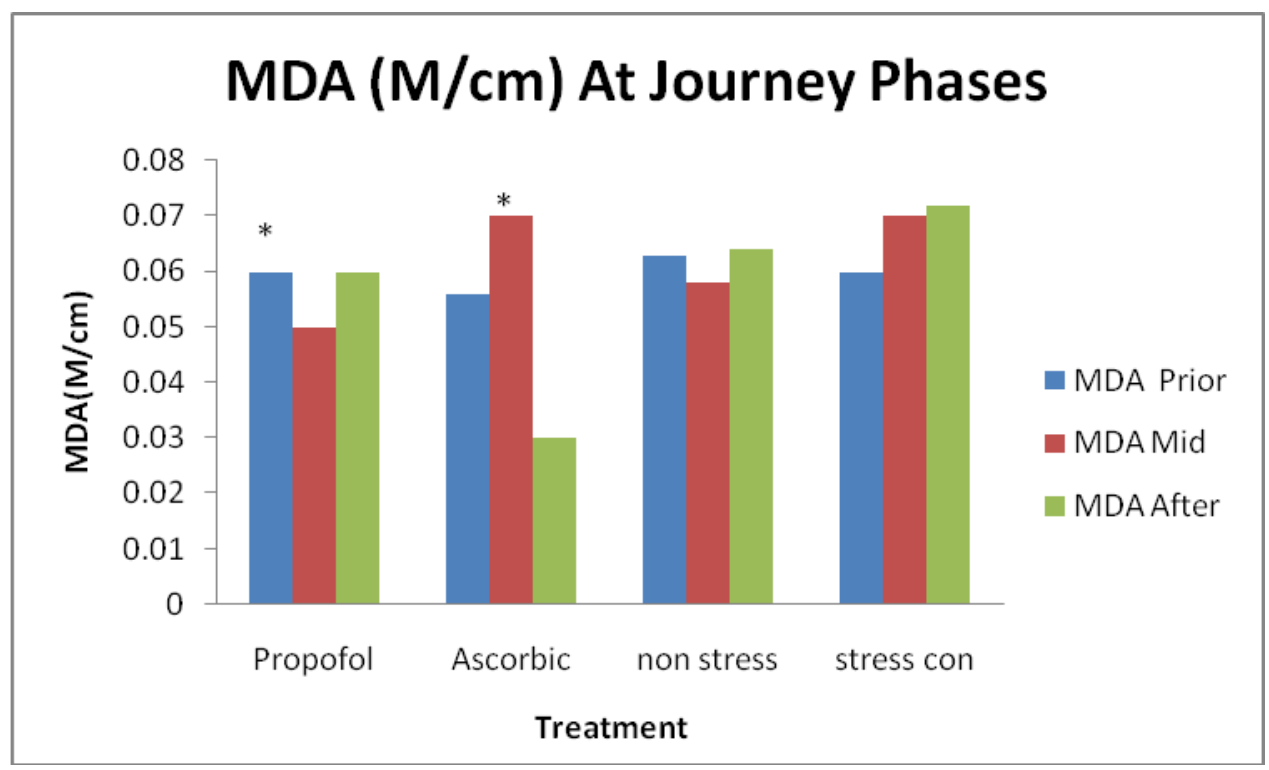

Figure 5. Shows the effect various treatment groups: Propofol $(5 \mathrm{mg} / \mathrm{kg})$ intramuscularly (IM), Ascorbic: ascorbic acid $(500 \mathrm{mg} / \mathrm{kg})(\mathrm{IM})$, non stress: non stress control, stress con: stressed control on means of malonyldialdehyde activity (MDA) $\mathrm{M} / \mathrm{cm}$ at various phases of the experimental journey MDA Prior: MDA prior to the journey MDA Mid: MDA midway into the journey and MDA After: MDA after the journey.

\section{GST (U/ml) At Journey Phases}

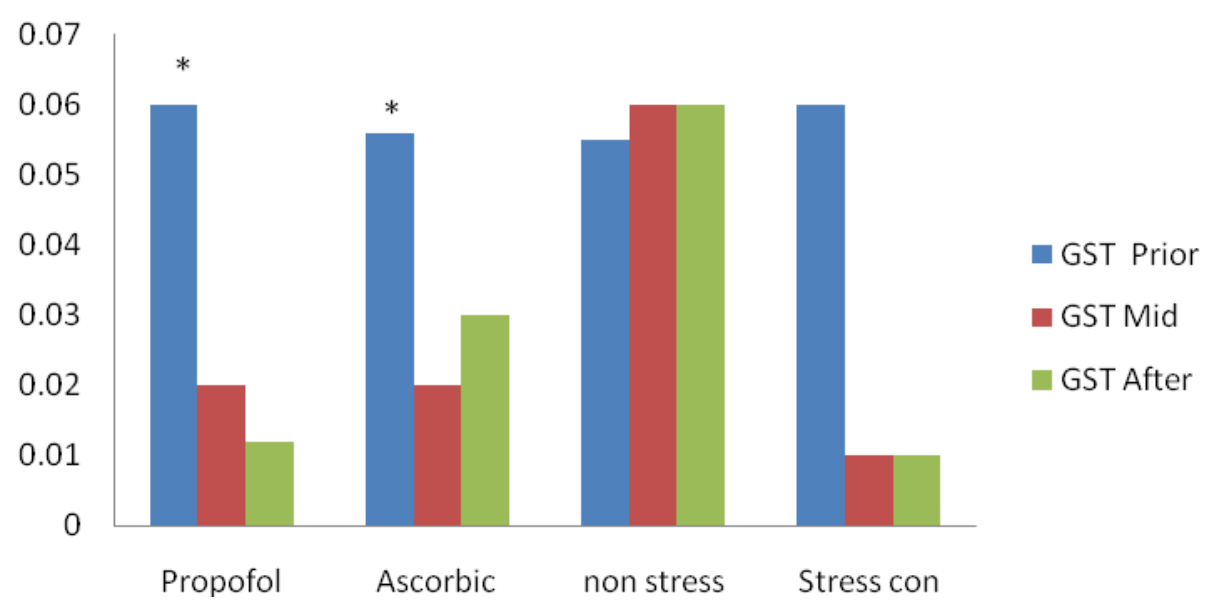

Figure 6. Shows the effect various treatment groups : Propofol $(5 \mathrm{mg} / \mathrm{kg})$ intramuscularly (IM),Ascorbic: ascorbic acid $(500 \mathrm{mg} / \mathrm{kg}$ ) (IM),non stress: non stress control, stress con: stressed control on means of glutathione-S-transferase (GST) (U/ml) activity at various phases of the experimental journey GST Prior : GST prior to the journey GST Mid:GST midway into the journey and GST After: GST after the journey . 


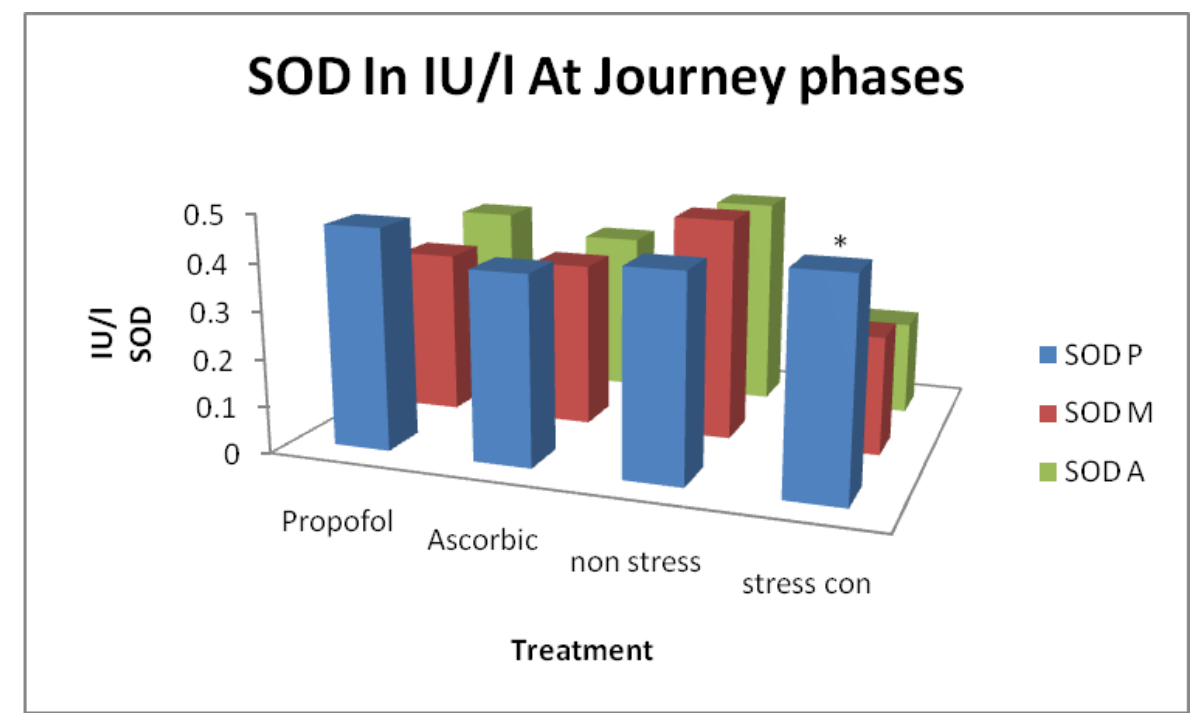

Figure 7. Shows the effect various treatment groups: Propofol $(5 \mathrm{mg} / \mathrm{kg})$ intramuscularly (IM), Ascorbic: ascorbic acid $(500 \mathrm{mg} / \mathrm{kg})(\mathrm{IM})$, non stress: non stress control, stress con: stressed control on means of superoxide dismutase (SOD) (IU/l) activity at various phases of the experimental journey SOD P : SOD prior to the journey SOD M: SOD midway into the journey and SOD A: after the journey.

In this study, the propofol manifested a similar antioxidative effect as the ascorbic acid on the PCV at stress of transportation. The explanation for this is the enhanced scavenging effect of these drugs on the ROS that would have been detrimental to the integrity of the erythrocytes membrane in the animals at stress. Both drugs prevented haemolysis that might have resulted due to changes in the fluidity of the cellular membrane caused by stress simulated by radicals. The propofol would have spared the antioxidants that would aid in stabilizing the membrane conformation of the erythrocyte. This observation might be a reflection of the antistress effect of propofol on erythrocytes in this study. This deductions made from this study was in line with the previous work of Shibakawa et al. (2005), who observed the anti-oxidative enhancement ability in his study in tissue culture .

The ascorbic acid in the same vein resulted in elevated the concentration of the anti-oxidative enzymes in the cells. The haematinic effect of ascorbic might involve the formation of complexes of ascorbate with iron ion in serum and could improve the PCV of the animal (Minka et al., 2010b)

The haemoglobin concentration was improved upon by propofol in the animals subjected to two hours stress. This gives credence to the fact that finding in the erythrocytic values might have been influenced by the antioxidative enhancing inherent pharmacologic effect of propofol (Lee and Kim, 2012). In addition to the antioxidative enhancing effect of propofol, the drug manifested its calming effect in the animals which prevented aggressive behaviour, struggling and haemorrhages that would have been detrimental to the metabolic changes during the alarm reaction in the early stage of transportation involving adrenaline surge and other catecholamine's. Propofol protected the adverse effect that would have been a secondary cause of blood loss and decrease in haemoglobin level. The propofol might have prevented the adverse effect of production of cytokines such as interleukin-6(IL-6), IL-4 and other cytokines through the modulation of cellular endogenous anti-oxidative enzymes. So this might also prevent extravasations of the erythrocytic components into the weak, permeable, compromised walls of the capillaries of animals exposed to stress of transportation. So, this could be beneficial to the haemoglobin concentration at stress. The increase in WBC at the interface of the journey is associated with the immunomodulatory effect of ascorbic acid in the animals exposed to stress in the groups that were administered with ascorbic acid. This observation is agreement with the previous work of Minka et al. (2010a) that observed the immunomodulatory effect of ascorbic acid in goats subjected to stress of transportation. 
In the same vein, the propofol also decreased the neutrophils-lymphocytes ratio $(\mathrm{N}$ : $\mathrm{L})$ which is amongst the haematological stress markers. It is evident that the propofol antistress effect was elicited on the $\mathrm{N}$ : $\mathrm{L}$ by causing a decline in the surge of the peripherally and centrally acting catecholamines that would have affected the haemogram at stress and invariably the N: L. This also could be associated with the neuroendocrine modulative effect of propofol on the nerves of the animals subjected to stress. Since these drugs cause changes in the dynamics of the surges of neurotransmitters at the alarm of stress, this could further trigger changes in the levels of cortisol surge which could affect the percentages of various leucocytes which was reflected upon the $\mathrm{N}$ : $\mathrm{L}$ in this study

The ameliorative effect of propofol on the concentration of the GST after the journey in the groups treated with propofol shows the ameliorative effect of propofol which is similar to the ascorbic acid effect. Thus, this infer that propofol possess antistress effect and could be used to improve animal welfare at transportation. Conclusively, the propofol possess antistress effect that is similar in mechanism to ascorbic acid and could be used in amelioration of stress in short term stress in animals. It however advised that the withdrawal period of the drug is adhered to prevent residue of drug in the meat product.

\section{REFERENCES}

1. Adenkola AY, Ayo JO, Sackey AKB and Adelaiye AB (2011). Eight hours road transportation and ascorbic acid administration effects on the haematological parameters of pigs during the Harmattan season. Agricultural and Biology Journal of North America 2: 1143-1150

2. Adenkola YA, Ayo JO, Sackey AKB, Adelaiye AB and Minka NS (2009). Excitability Scores of pigs administered ascorbic acid and transported during harmattan season. Veterinarski Archive 79: 471-480.

3. Ali BH, Al-Qarawi AA and Mousa AM (2006). Stress associated with road transportation in desert sheep and goats and the effect of pre-treatment with xylazine and sodium betaine. Research in Veterinary Science 80: 343-348.

4. Ali BH and Al-Qarawi AA (2002). An evaluation of drug used in control of stressful stimuli in domestic animals: A Review Acta Veterinary Burno 71: 205-216.

5. Animal Disease control Act 10, (1988). A Publication of Federal Ministry of Agriculture, Garki, Abuja, Nigeria

6. Ayo JO, Minka NS and Mamman M (2006). Excitability scores of goats administered ascorbic acid and transported during hot-dry conditions. Journal of Veterinary Sciences 7:127-131.

7. Biobaku KT (2015). Effect of xylazine and ascorbic acid co-administration on transportation stress and meat characteristics in Sahel bucks. A Ph.D Thesis submitted to the Post graduate school, Usmanu Danfodiyo University, Sokoto, Nigeria.

8. Hama-Tomioka K, Kinoshita H, Nakahata K, Kondo T, Azma S, Kawahito N, Hatakeyama and Matsuda N (2011). Roles of neuronal nitric oxide synthase, oxidative stress, and propofol in N-methyl-D-aspartate-induced dilation of cerebral arterioles. http://bja.oxfordjournals.org

9. Lee JY and Kim MC (2012). Effect of propofol on oxidative stress status in erythrocytes from dogs under anaesthesia. Acta Veterinaria Scandinavica 54: 76

10. Minka NS and Ayo JO (2010a). Serum biochemical activities and muscular soreness in transported goats administered with ascorbic acid during the hot-dry season. European journal of Transitional Myology-Basic Applied Myology 1: 193-203.

11. Minka NS and Ayo JO (2010b). Physiological responses of food animals to road transportation stress. African journal of Biotechnology 9: 6601-6613.

12. Mohammed A, George L and Mustapha FL (2007). Exercise decreases oxidative stress and Inflammation and restores renal dopamine D receptor function in rats. American Journal of Physiology and Renal Physiology 293: 914-919.

13. Sandhu HS (2014). Essentials of Veterinary Pharmacology and Therapeutics. $2^{\text {nd }}$ edition, Kalyanani, New Delhi, India. 280-282.

14. Schalm S and Jain NC (1986). Veterinary haematology $4^{\text {th }}$ edition, Lea fabriger, Philadephia. 564-574.

15. ShibakawaYS, Sasaki Y, Goshima Y, Echigo N, Kamiya K, Kurahashi YY and Andoh T (2005). British Journal of Anaesthesia 95: 803-10

16. SPSS (2006). Statistical package for social sciences Version 16 SPSS Inc.

17. Wen-fang X, Yu L, Qing-shan Z, Qi-Zhu T and Han-dong Z (2011). Comparison of effects of propofol and midazolam on inflammation and oxidase stress in children with congenital heart disease undergoing cardiac surgery. Yonsei Journal of Medicine 52: 326-332 